\title{
Exploration of Applying Lego NXT and Arduino in Situated Engineering Teaching: A Case Study of a Robotics Contest at King Saud University
}

\author{
Haykel Marouani a,b,1,* \\ ${ }^{a}$ College of Engineering, Muzahimiyah Branch, King Saud University, P.O. Box 2454, Riyadh 11451, Saudi Arabia \\ ${ }^{\mathrm{b}}$ University of Monastir, LGM, ENIM, Avenue Ibn-Eljazzar, 5019 Monastir, Tunisia \\ 1 hmarouani@ksu.edu.sa \\ * Corresponding Author
}

\section{ARTICLE INFO}

\section{Article history}

Received November 21, 2021

Revised January 06, 2022

Accepted January 30, 2022

Keywords

Adult learning;

Improving classroom teaching;

Teaching/learning strategies

\begin{abstract}
Saudi students in engineering courses suffer from a lack of science, technology, engineering, and mathematics (STEM) knowledge due to the teaching philosophy and programs offered in secondary and intermediate schools. This weakness naturally impacts their motivation, grades, and their relationship with teachers. In this paper, we introduce a new experimental teaching experience in the Applied Mechanical Department of the Applied Engineering College of King Saud University, based on situated learning theory, which emphasizes that knowledge must be learned in constructed situational context). This experience involved introducing Lego NXT and Arduino to enhance the enthusiasm and interest of students through designing and building robots in agreement with the "Introduction to design" course syllabus. Two experimental challenges were associated with: the line-follower problem and the maze problem. These challenges took the form of an internal completion at the end of each semester. The experience was conducted for two consecutive terms (30 students, the academic year 2019-2020), and the results were compared to those in six previous terms (100 students, academic years from 2016 to 2019). The experimental group demonstrated grades improvement (course mean grade rose from 77.1 to 85.3), the progress of academic achievement, and interest that enables them to actively explore and construct knowledge.
\end{abstract}

This is an open-access article under the CC-BY-SA license.

\section{Introduction}

For decades, Saudi Arabia has invested in local and governmental universities and developed a number of world-class institutions. Twelve Saudi universities are ranked in the QS World University Rankings ${ }^{\circledR}$ in 2021 (against seven in 2020), including King Abdulaziz University (ranked 143), King Fahd University of Petroleum \& Minerals (ranked 186), and King Saud University (ranked 287). According to the 2018 edition of the QS Higher Education System Strength Rankings, the kingdom has also been featured as having the 36th best higher education system in the world. However, academics and the educational system are facing difficulties in motivating students in the learning process, especially in the field of engineering. One of the main reasons for this is that the primary and secondary education systems are not making enough effort to teach science, technology, engineering, 
and mathematics (STEM). This lack of a STEM background harms engineering students' grades and grade point average during their undergraduate studies. As a King Saud University academic (member of the Applied Mechanics Department of the Applied Engineering College since 2016), I have faced the same problems in teaching and motivating students during my lectures. I noticed that the academic achievement of the majority of my students is insufficient and sometimes poor. For that reason, I decided to enrich one of my courses by introducing robotics to stimulate students' ability to solve engineering problems.

Teaching is no longer limited to just passing on knowledge but should include students developing the abilities of problem-solving, creativity, and logical reasoning [1]-[3]. Fortunately, with the assistance of new technologies, some learning theories are easier to fulfill, and teachers have more options regarding teaching aids for achieving better learning effects. In the teaching of mechanical engineering, new learning technologies can be based on robotics, which can help to create learning situations. Literature survey on educational robotics application grounded on learning theories shows that robots are an alternative to support teaching and developing topics not directly related to robotics, such as programming, teamwork, mechanics, automata theory, problem-solving, cognitive processes, and basics physics [4]-[6]. Arduino and Lego NXT are among the newly developed and highly appreciated educational toys for science used from early childhood [7]-[10] to university [11]-[14]. For example, the philosophy of Lego robotics design originates from constructivism [15] and Seymour Papert's constructionism [16]; its aim is to enable children/students to obtain knowledge of mathematics and science by designing and manipulating Lego robotics. Meanwhile, it helps children to cultivate their problem-solving ability and creativity in the thinking process. Arduino is also derived from a philosophy of learning by doing and strives to make it easy to work directly with the medium of interactivity. It extends the principles of open source to the realm of hardware, supporting a community of people working with and extending the platform. Thus, both Arduino and Lego NXT were selected to simulate the actual situation in the learning process described in this paper. My approach is based on situated learning theory.

Situated learning theory [17] claims that knowledge is contextually situated and is influenced by the context, activity, and culture in which it is used. When teaching in universities, especially for engineering students, teachers need to provide a great amount of knowledge in a short time and often present knowledge concepts detached from any real-world situation, thereby creating only temporary learning effects. When students are later situated in an actual engineering-related scenario, they often need to relearn the relevant knowledge, which means that the knowledge learned in a detached scenario cannot be implemented in a real situation. It is also known that an individual's recognition originates from the process of external social interactions, and problem-solving ability and decisionmaking ability are deeply influenced by the cultural and social environment [18]. Therefore, without the knowledge of social cultures and situational contexts, learning is not complete.

Situated learning theory emphasizes that knowledge must be learned in constructed situational contexts. Knowledge is meaningful if it is generated from applying it to a situation and is explained in a situation. In this way, learners can actually apply the knowledge as well as facilitate their understanding and memory. During the process of acquiring knowledge, situated learning theory stresses the initiative of the learner. Through authentically situated activities, students generate interests that enable them to actively explore and construct knowledge instead of passively accepting external stimuli. Therefore, students can understand the meaning and implication of the knowledge. When knowledge is constructed in an authentic environment, learners can understand the meaning of the knowledge and construct individual recognition history through interaction with the situation, which can facilitate the transfer and implication of the knowledge to learners [19], [20]. Moreover, in the process of situated learning, teachers play an important role, and the relationship between teachers and students is similar to the traditional relationship between masters and apprentices. Students actively engage in the situation, observing and imitating teachers, in order to construct their own knowledge and skills. Teachers are subsidiaries, guides, trainers, and consultants, investigating and scaffolding to support students' learning when students encounter problems. Therefore, all aspects may influence learners' views, motivation, and learning strategies, including teachers' teaching 
strategies, their beliefs, their expertise in the subject area, their instructions, and students' interaction [21]-[23].

According to [24], there are four major principles of activity design of situated learning theory: Stress on the authenticity of the learning activity, stress on the active inquiry and operation, stress on the role of teachers, and interaction with the social culture. In this paper, I present the findings upon introducing the use of robotics to enhance the enthusiasm, interest, motivation, academic achievement, and grades of students at the Applied Engineering College of King Saud University. The Engineering Design course was chosen to contain the new learning activities. For experimental and control groups, the current and previous crops of students following this course were selected. The research contributions are quantitative and qualitative. Firstly, we quantified the impact of situated learning on the student's grades by the introduction of a new robotics-based teaching approach. Then, motivation, interaction, and stimulation of Saudi students were extended.

The rest of the paper is arranged as follows. The course specification and learning difficulties are cited in section 2. Section 3 describes the methodology of the research. Data analysis is detailed in section 4 , while conclusions are summarized in section 5 .

\section{Engineering Design Course and Learning Difficulties}

Engineering Design is a level 8 course (out of 10 levels) taught for the undergraduate applied engineering program that leads to the Bachelor of Engineering degree in the Applied Engineering College of King Saud University (Saudi Arabia). The course aims are to expose students to engineering design, to adhere to professional standards, to give practical experience solving openended problems, to identify the important variables, and to use the design process and problem-solving skills. It is organized as 1-hour lectures and 1-hour tutorials. The topics to be covered during the term are listed in Table 1.

Table 1. Engineering Design topics

\begin{tabular}{cc}
\hline Week number & Topic \\
\hline 1 & Lesson 1: Engineering design and engineering process \\
\hline 2 & $\begin{array}{c}\text { Lesson 2: Problem definition: detailing customer requirements, clarifying the } \\
\text { objectives, and identifying constraints }\end{array}$ \\
\hline 3 & Lesson 4: Conceptual design: generating and evaluating design alternatives \\
\hline 5 & Lesson 5: Communicating design graphically \\
\hline 6 & Lesson 6: Prototyping and proofing the design \\
\hline 8 & Lesson 7: Communicating design orally and in writing \\
\hline 10 & Lesson 8: Mathematical modeling in design \\
\hline 11 & Lesson 9: Engineering economics in the design \\
\hline 12 & Lessign for production, use, and sustainability \\
\hline 13 &
\end{tabular}

According to the course specification, the assessment is based on quizzes, assignments, and projects. I have taught this course since the academic year 2016/2017 up to the present. Since the first term, I reported difficulty motivating my students. The reasons for this were that this course is $100 \%$ theoretical, and there is no science application or physical implementation. This disinterest was 
directly affecting the students' grades. This was a problem that I did not face during my previous experiences in teaching in France and Tunisia in engineering colleges. For this reason, I decided to introduce robotic learning, starting from the first term of the academic year 2019/2020, in order to challenge the students and enhance their performance.

\section{Method}

\subsection{Sample}

The research sample is the crops of students taught from 2016 in the Applied Mechanics Department at the Applied Engineering College of King Saud University. The students are males aged 21-23 years old. The experimental group is the students taught during the 2019-2020 academic year (30 students). The control group is the students taught from 2016 to 2019 (100 students). Table 2 describes the number of students per term.

Table 2. Distribution of the number of students per semester

\begin{tabular}{ccc}
\hline Academic year & Term & Number of students \\
\hline \multirow{2}{*}{$2016-2017$} & 1 & 15 \\
\cline { 2 - 3 } & 2 & 22 \\
\hline \multirow{2}{*}{$2017-2018$} & 1 & 13 \\
\cline { 2 - 3 } $2018-2019$ & 2 & 21 \\
\hline \multirow{2}{*}{$2019-2020$} & 1 & 9 \\
\cline { 2 - 3 } & 2 & 20 \\
\hline
\end{tabular}

\subsection{Design of Teaching}

The new experimental teaching activities involved using robotics and applying STEM in engineering design with respect to the original course syllabus. Two experimental challenges were associated with this: the line-follower problem and the maze problem. These challenges took the form of an internal competition at the end of each semester.

I used the lectures to present the theoretical part of the course (to preserve the same content for the experimental and control groups), while I dedicated the tutorials to introducing the new experimental teaching activities. In the first week, I enriched lesson 1 (Engineering design and engineering process) by discussing robotics and introducing the use of robots in the line-follower and maze challenges. In the online learning management system (Blackboard), I uploaded some videos of student competitions worldwide to sensitize the students to this topic and to show them what is going on in the rest of the world. I also presented Lego NXT and Arduino to them. For 29 students (from 30), it was the first time that they had heard about robotics, Arduino, Lego NXT, and robotics challenges. Lesson 2 (Problem definition: detailing customer requirements, clarifying the objectives, and identifying constraints) was an interesting opportunity to achieve interaction and constructive discussion to define the challenge specifications. At the end of Week 3, teams were defined (3-4 students per team), and challenges were assigned. Some teams chose to compete in one single challenge, while some highly motivated teams chose to compete in both challenges. During lesson 3 (Problem definition: establishing functions), we associated the problem definition with our robots by defining what functions each type of robot should perform. Then, during lesson 4 (Conceptual design: generating and evaluating design alternatives), we discussed, criticized, and improved different conceptual designs by generating and evaluating design alternatives. Week 7 (i.e., lesson 5: Communicating design graphically) was the opportunity for the students to present their final design. They used free sketches, AutoCAD, and Solidworks. AutoCAD and Solidworks were taught during level 3 and level 5, respectively (i.e., the Introduction to Engineering Drawing course and Mechanical 
Engineering Drawing course). Weeks 8 and 9 (Lesson 6: Prototyping and proofing the design) were dedicated to the robot assembly and programming using Arduino and Lego NXT. This part required extra engagement from all of the students to complete the required tasks in the allotted time. Lesson 7 (Communicating design orally and in writing) was dedicated to team-by-team presentations of the progress of their work. During weeks 11 and 12 (Lesson 8: Mathematical modeling in design), I presented and suggested some improvements to the students' work. I started by asking them what they had learned in their previous courses, such as "Dynamics," "Mechanics of Machinery," and "System Dynamics and Control." Then, we decided to incorporate some mathematical modeling as PID control (Proportional, Integral, Derivative) to achieve better motion of the robots. Finally, the teams submitted their final report, including an economic evaluation of their robot, in accordance with what we had discussed in lecture 9 (Engineering economics in design). The last week of the semester was dedicated to the competition, which was also open to students from other levels of the Applied Engineering College. All of these situated learning activities are summarized in Table 3.

Table 3. New experimental teaching activities schedule

\begin{tabular}{cc}
\hline Topic & New associated experimental teaching activities \\
\hline $\begin{array}{c}\text { Lesson 1: Engineering design and engineering process } \\
\text { constraints }\end{array}$ & Presentation of the line-follower and maze challenges \\
\hline $\begin{array}{c}\text { Lesson 2: Problem definition: detailing customer } \\
\text { requirements, clarifying the objectives, and identifying }\end{array}$ & Challenge specification \\
\hline Lesson 3: Problem definition: establishing functions & Robot function definition \\
\hline $\begin{array}{c}\text { Lesson 4: Conceptual design: generating and evaluating } \\
\text { design alternatives }\end{array}$ & Discussion of design alternatives \\
\hline Lesson 5: Communicating design graphically & Final design presentation using engineering drawing \\
\hline Lesson 6: Prototyping and proofing the design & Robot assembly, programming, and testing in real situations \\
\hline $\begin{array}{c}\text { Lesson 7: Communicating design orally and in writing } \\
\text { Lesson 8: Mathematical modeling in design }\end{array}$ & $\begin{array}{c}\text { Presentation of the work progress (Word report and } \\
\text { PowerPoint presentation) }\end{array}$ \\
\hline Lesson9: Engineering economics in the design & $\begin{array}{c}\text { Adding the economic study for each robot and submitting } \\
\text { the final report and presentation }\end{array}$ \\
\hline Lesson 10: Design for production, use, and \\
sustainability
\end{tabular}

The new experimental teaching activities were introduced weekly during the semester, and the aim was to allow students to undertake learning activities in a stimulating situation by using Lego NXT and Arduino. This teaching design is centered on how to apply "engineering design" outcomes in order to succeed in robotics challenges so that students can integrate the learned knowledge and situation.

The students in the experimental group had no experience of using Lego Robotics or Arduino. They had also never designed or edited programs in Lego Robotics or Arduino. For that reason, my role as the teacher was a key factor in the success of the teaching strategy. Indeed, the relationship between teachers and students in the process of situated learning has been reported to be significant [25]. During the process, students imitate teachers' behaviors and ask for teachers' help when encountering problems. Learning can proceed smoothly in this learning environment.

During the situated teaching activities, I demonstrated all of the procedures, provided positive or negative feedback to the students' learning behaviors, and gradually reduced assistance for them to solve problems by themselves so as to achieve better learning effects. Students learned in groups in class through discussing, creating, and sharing each other's thoughts in groups, which is emphasized in both situated learning theory and constructionism. 


\section{Data analysis}

This section describes the fulfillment of the robotic challenge by the students and the impact of the new experimental situated learning activities on the students' grades and state of mind.

\subsection{Robotic Challenge}

Two challenges we're prepared for the students: line-follower (Fig. 1(a)) and maze (Fig. 1(b)). For the first one, student groups were challenged to program robots with infrared or color sensors to follow a black line with a relatively difficult path. The line-follower concept has applications for running mass transit systems and autonomous cars on highways, as well as delivering mail in office buildings, move items through factory assembly lines, and deliver medications in hospitals. For the second one, students were introduced to the logic for solving a maze. Programming a robot to navigate a maze is similar to real-world engineering design projects, such as controlling a Mars Rover to explore the planet's surface. Engineers design robots to carry out tasks in locations that are dangerous for people, such as in ocean depths, volcanoes, factories, and war zones, and to provide reconnaissance and aid in natural and human-made disasters.

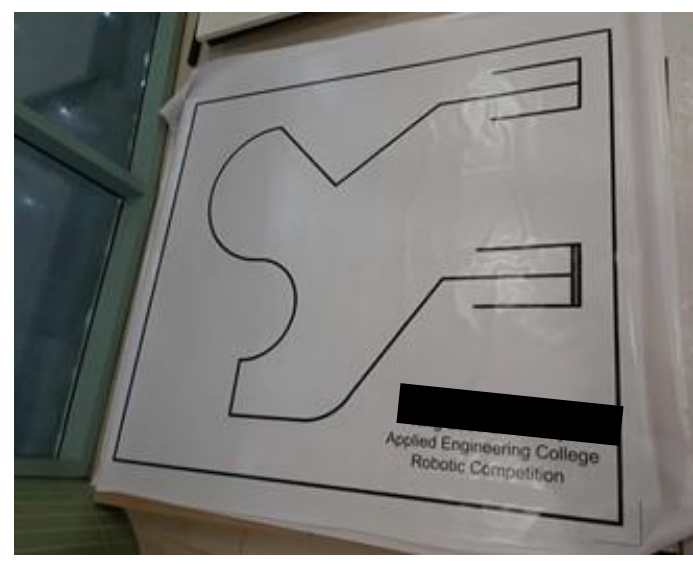

(a)

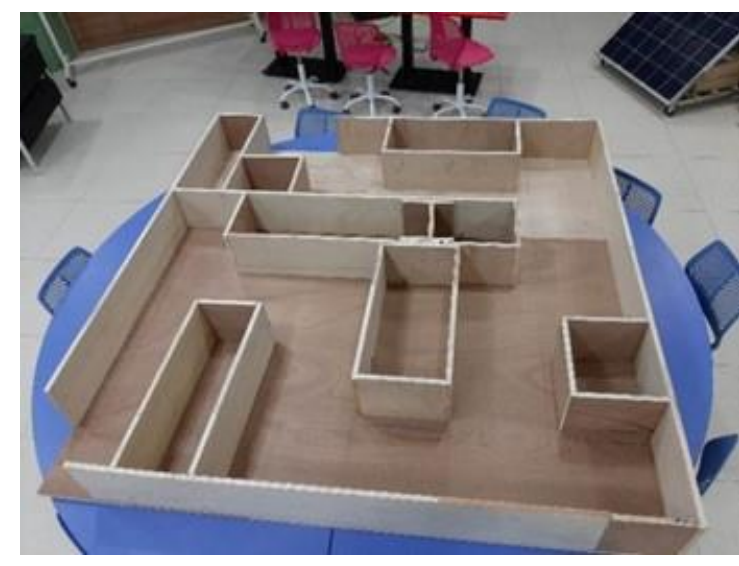

(b)

Fig. 1. Challenge fields: (a) line-follower and (b) maze

For the first term, the 11 students were divided into three teams (3-4 students per team). All teams chose to participate in the line-follower challenge. For the second term, the 19 students were divided into six teams (3-4 students per team). Two teams selected the line-follower challenge, two the maze challenge, and two decided to participate in both.

Owing to the lack of knowledge on robotics, programming, and the use of Lego NXT and Arduino, I offered 3-day training $(18 \mathrm{~h}$ ) for Arduino and did the same for Lego NXT during the introduction week of each term (first week). Fig. 2-Fig. 5 shows some of the robots designed and assembled by the students.
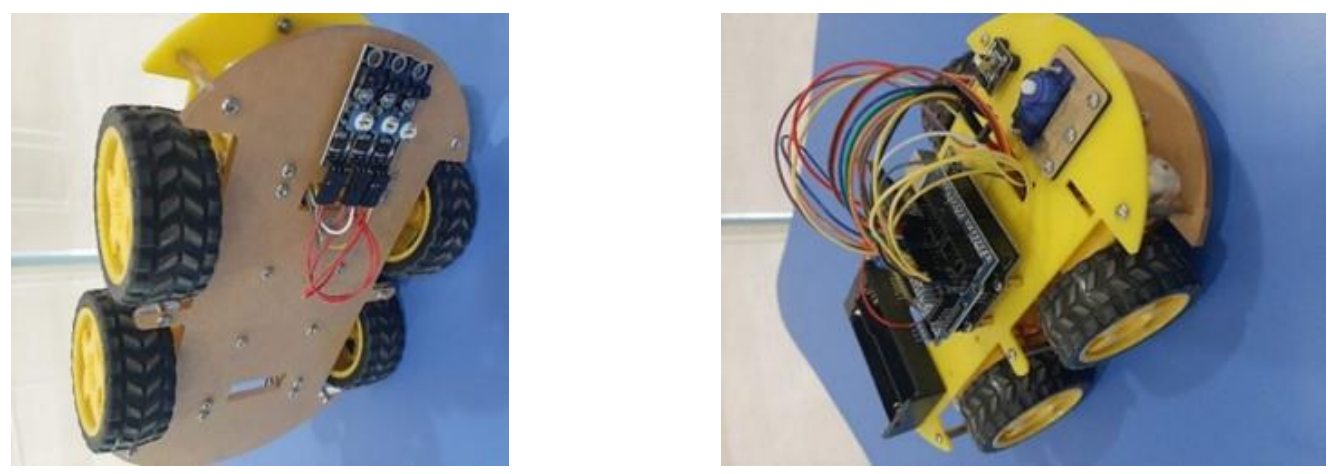

Fig. 2. Some students' robots for the line-follower challenge using Arduino 

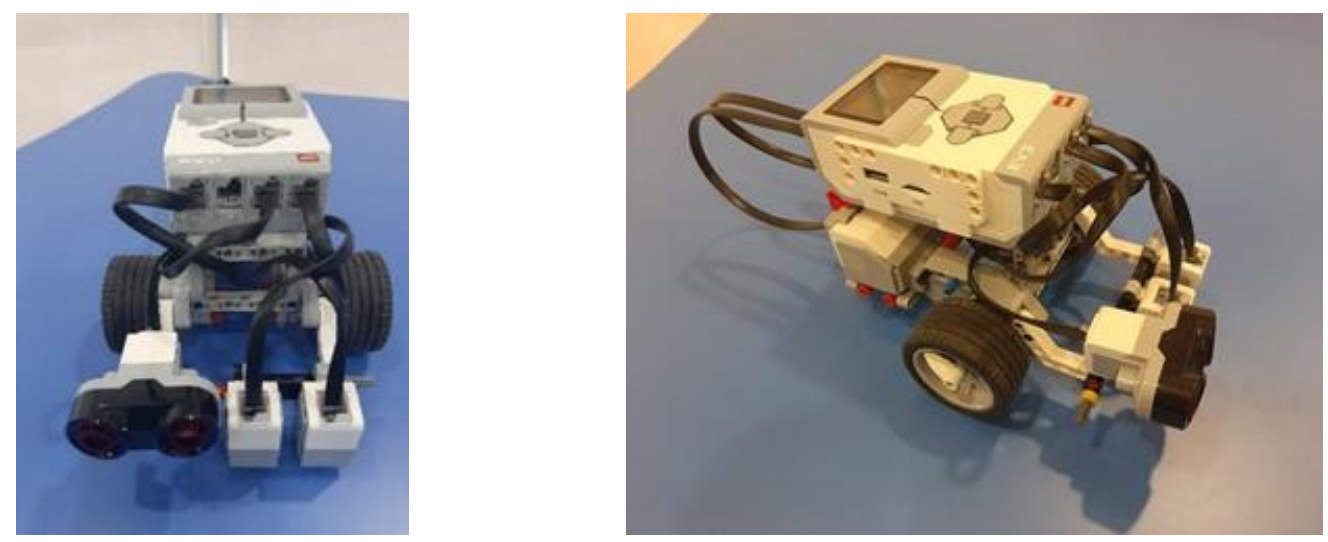

Fig. 3. Some students' robots for the line-follower challenge using Lego NXT

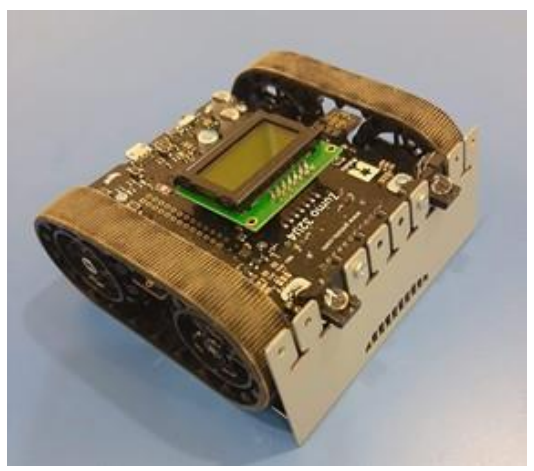

Fig. 4. One of the robots used for the maze challenge using Arduino (Pololu Zumo Robot)
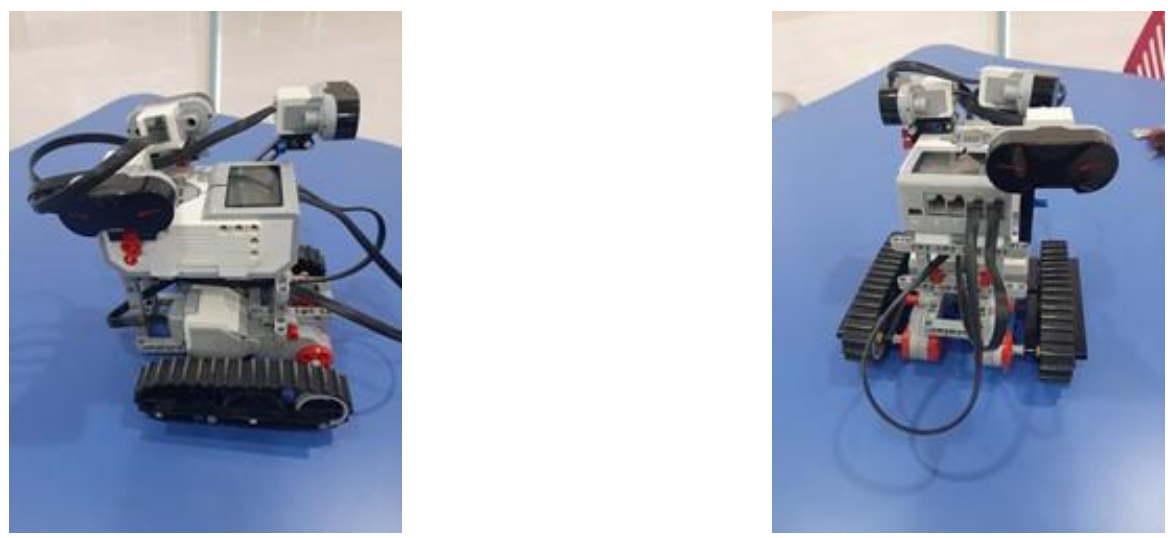

Fig. 5. Some students' robots for the maze challenge using Lego NXT

\subsection{Students' Grade Evolution}

Since spring 1996, academic grading in Saudi Arabia has commonly taken the form of five letter grades (Table 4). One of the major objectives of this experience is to study the impact of such a situated learning strategy on the students' grades. Table 5 shows the grade distribution for the control group (students from academic years 16/17 to 18/19) and the experimental group (students from academic year 19/20). We note that, during the six terms, no students were able to obtain A+ in the control group and generally at least one student failed the course. However, for the experimental group, the global performance was much better: no students failed, the worst grade was D+, and some students managed to get A+. Table 6 shows the mean grades and the standard deviation for each group. This information is used to depict the normal distribution (Fig. 6). 
Table 4. University grading in Saudi Arabia

\begin{tabular}{ccc}
\hline Grade letter & Grade percentage & Grade description \\
\hline A + & $95-100$ & Exceptional \\
\hline A & $90-94.99$ & Excellent \\
\hline B & $85-89.99$ & Superior \\
\hline B & $80-84.99$ & Very good \\
\hline C + & $75-79.99$ & Above average \\
\hline C & $70-74.99$ & Good \\
\hline D+ & $65-69.99$ & High pass \\
\hline D & $60-64.99$ & Pass \\
\hline F & $<60$ & Fail
\end{tabular}

Table 5. Grade distribution

\begin{tabular}{cccccccccc}
\hline & & $\mathbf{1 6} / \mathbf{1 7}$ & & $\mathbf{1 7 / 1 8}$ & & $\mathbf{1 8 / 1 9}$ & & $\mathbf{1 9 / 2 0}$ \\
\cline { 2 - 8 } & $\mathbf{1}$ & $\mathbf{2}$ & $\mathbf{1}$ & $\mathbf{2}$ & $\mathbf{1}$ & $\mathbf{2}$ & $\mathbf{1}$ & $\mathbf{2}$ \\
\hline A+ & 0 & 0 & 0 & 0 & 0 & 0 & 1 & 2 \\
\hline A & 1 & 2 & 1 & 2 & 1 & 2 & 2 & 3 \\
\hline B & 0 & 1 & 2 & 2 & 1 & 3 & 1 & 3 \\
\hline B & 2 & 2 & 1 & 1 & 2 & 1 & 2 & 3 \\
\hline C & 6 & 4 & 3 & 5 & 1 & 4 & 3 & 4 \\
\hline C & 2 & 6 & 1 & 3 & 1 & 3 & 1 & 3 \\
\hline D+ & 1 & 2 & 2 & 4 & 1 & 3 & 1 & 1 \\
\hline D & 2 & 3 & 2 & 3 & 2 & 3 & 0 & 0 \\
\hline F & 1 & 2 & 1 & 1 & 0 & 1 & 0 & 0 \\
\hline
\end{tabular}

Table 6. Grade mean and standard deviation per term

\begin{tabular}{cccc}
\hline Academic Year & Semester & Mean & Standard deviation \\
\hline \multirow{2}{*}{$2016 / 2017$} & 1 & 76.9 & 8.9 \\
\cline { 2 - 4 } & 2 & 76 & 9.9 \\
\hline \multirow{2}{*}{$2017 / 2018$} & 1 & 77.2 & 10.6 \\
\cline { 2 - 4 } & 2 & 76.9 & 9.9 \\
\hline \multirow{2}{*}{$2018 / 2019$} & 1 & 78.9 & 10.2 \\
\hline \multirow{2}{*}{$2019 / 2020$} & 2 & 77.7 & 10.4 \\
\cline { 2 - 4 } & 1 & 85 & 8.8 \\
\hline
\end{tabular}

To better illustrate the improvement of grades, I summarize the results of the control group and the experimental one (Table 7). The mean and standard deviation are shown in Table 8. Fig. 7 depicts the normal distribution. The results confirm the grade improvement. The mean grade rose from 77.1 to 85.3 , with values that tended to be close to the mean (standard deviation decrease from 10 to 8.7). 

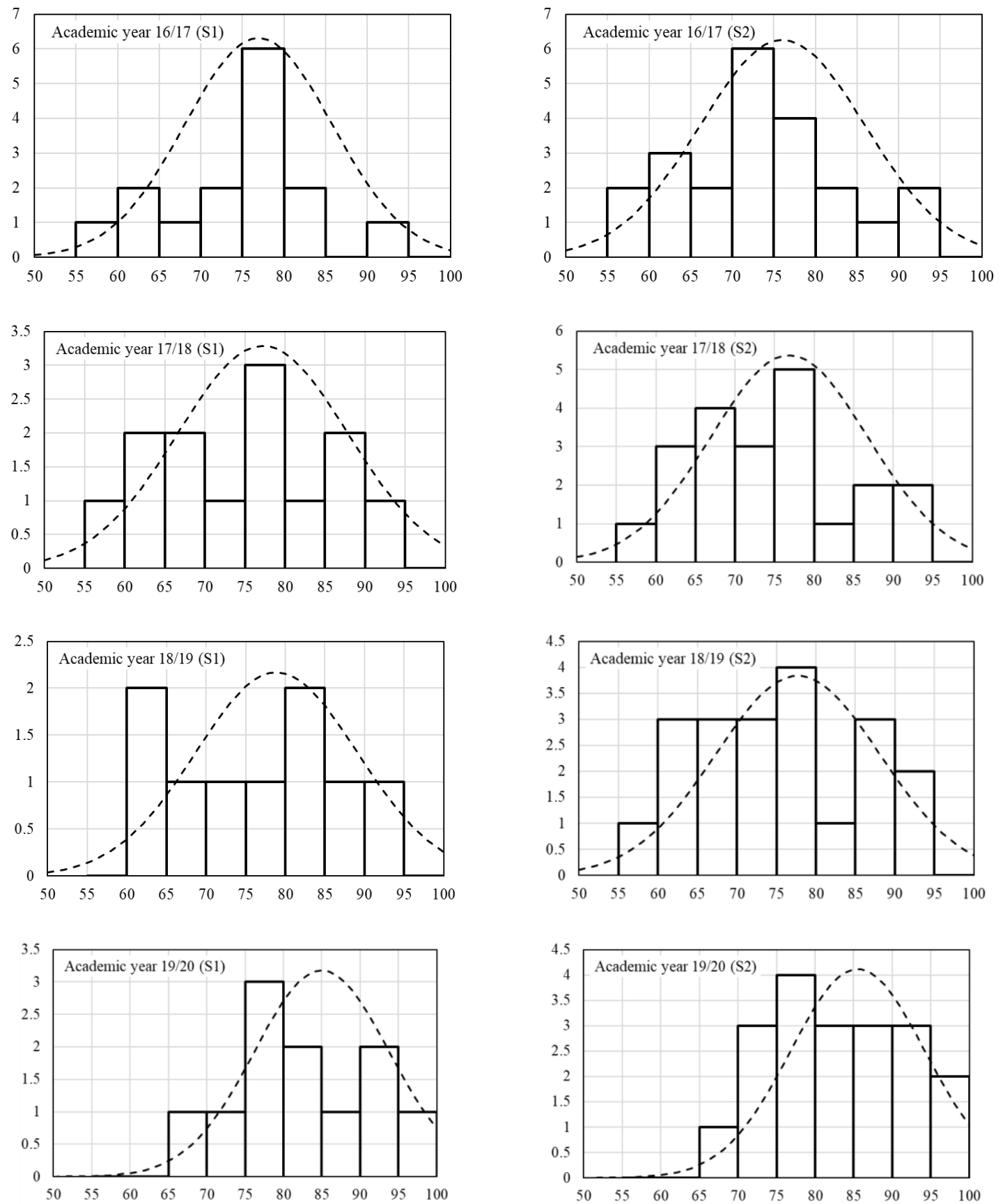

Fig. 6. Normal distribution of the grades per semester
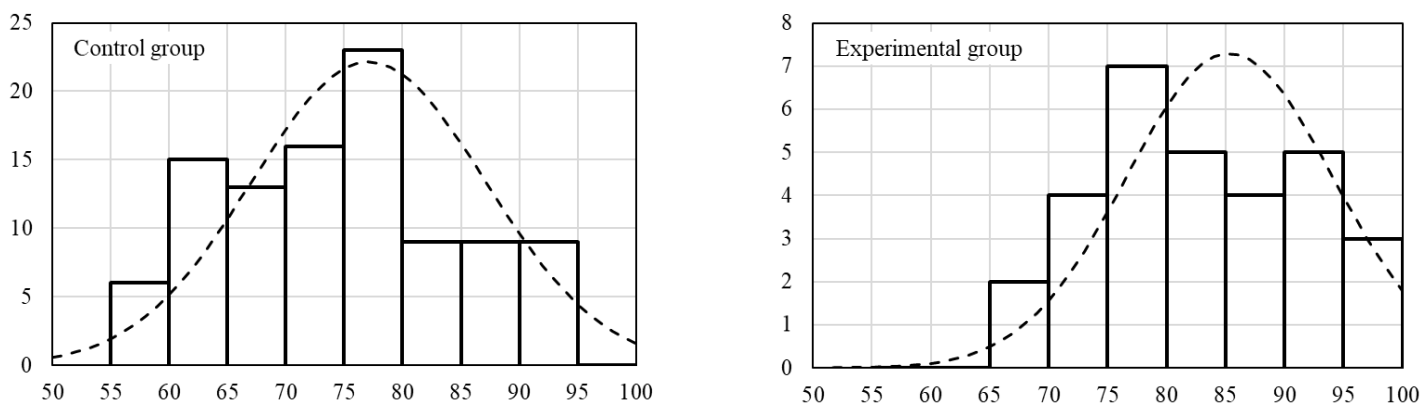

Fig. 7. Normal distribution of the grades for the control and experimental groups 
Table 7. Grade distribution for the control and experimental groups

\begin{tabular}{ccc}
\hline & Control group & Experimental group \\
\hline $\mathrm{A}+$ & 0 & 3 \\
\hline $\mathrm{A}$ & 9 & 5 \\
\hline $\mathrm{B}+$ & 9 & 4 \\
\hline $\mathrm{B}$ & 9 & 5 \\
\hline $\mathrm{C}+$ & 23 & 7 \\
\hline $\mathrm{C}$ & 16 & 4 \\
\hline $\mathrm{D}+$ & 13 & 2 \\
\hline $\mathrm{D}$ & 15 & 0 \\
\hline $\mathrm{F}$ & 6 & 0 \\
\hline
\end{tabular}

Table 8. Grade mean and standard deviation for the control and experimental groups

\begin{tabular}{ccc}
\hline & Mean & Standard deviation \\
\hline Control group & 77.1 & 10 \\
\hline Experimental group & 85.3 & 8.7 \\
\hline
\end{tabular}

\subsection{Students' State of Mind}

The first time I introduced the new learning experience, during the first term of the academic year 2019/2020, the students were reluctant to participate in it. They were aware of their weakness in robotics and programming and were afraid that this new teaching experience would adversely affect their grades. The three teams selected the line-follower challenge because they thought it would be easier (which is true when compared with the maze challenge), offering greater chances of success in the course. However, week by week, the interest and motivation of the students grew. For example, during the fifth week (task: Final design presentation using engineering drawing), the open-access college computer room was full of motivated and interested students. This was impressive and a rare occurrence. During weeks 8 and 9, students asked to stay late at the campus to finalize their work, and they sometimes asked for my assistance.

During the second term of the academic year 2019/2020, the students were impatient to start this challenge because of the good feedback that they had heard from the previous crop of students. They were more ambitious, and some of them signed up for the maze challenge or even for both challenges. I noticed the same motivation and same interest among them, which demonstrated that this learning strategy is very attractive and beneficial.

\section{Conclusion}

Situated learning theory asserts that knowledge is influenced by activities. In this study, robotics activities were introduced during the whole semester, and for two semesters, in a specific engineering course, to remodel the students' STEM knowledge in a constructed situational context. Lego NXT and Arduino were used to design and build robots in order to compete and generate interests that enable students to actively explore and construct knowledge instead of passively accepting external stimuli. This interest was immediately translated into academic achievement. Indeed, the global student grades were improved by $10.6 \%$, and positive feedback was reported. The lack of STEM knowledge identified among Saudi students shrank, and this experience could be generalized for application in different Saudi engineering colleges and even in secondary schools. In the next editions of experience, we aim to introduce new projects related to teaching manufacturing systems and industry 4.0 . 
Conflicts of Interest: The authors declare no conflict of interest.

\section{References}

[1] G. Y. M. Kao, C. H. Chiang, and C. T. Sun, "Customizing scaffolds for game-based learning in physics: Impacts on knowledge acquisition and game design creativity," Comput. Educ., vol. 113, 2017. https://doi.org/10.1016/j.compedu.2017.05.022

[2] S. F. Shawer, "Teacher-driven curriculum development at the classroom level: Implications for curriculum, pedagogy and teacher training," Teach. Teach. Educ., vol. 63, 2017. https://doi.org/10.1016/j.tate.2016.12.017

[3] E. Curtis, J. Lunn Brownlee, and R. Spooner-Lane, "Teaching perspectives of philosophical inquiry: Changes to secondary teachers' understanding of student learning and pedagogical practices," Think. Ski. Creat., vol. 38, 2020. https://doi.org/10.1016/j.tsc.2020.100711

[4] S. Kucuk and B. Sisman, "Students' attitudes towards robotics and STEM: Differences based on gender and robotics experience," Int. J. Child-Computer Interact., vol. 23-24, 2020. https://doi.org/10.1016/j.ijcci.2020.100167

[5] Y. W. Cheng, P. C. Sun, and N. S. Chen, "The essential applications of educational robot: Requirement analysis from the perspectives of experts, researchers and instructors," Comput. Educ., vol. 126, 2018. https://doi.org/10.1016/j.compedu.2018.07.020

[6] N. Spolaôr and F. B. V. Benitti, "Robotics applications grounded in learning theories on tertiary education: A systematic review," Comput. Educ., vol. 112, 2017. https://doi.org/10.1016/j.compedu.2017.05.001

[7] L. Xia and B. Zhong, "A systematic review on teaching and learning robotics content knowledge in K12,” Comput. Educ., vol. 127, 2018. https://doi.org/10.1016/j.compedu.2018.09.007

[8] B. Zhong and L. Xia, "A Systematic Review on Exploring the Potential of Educational Robotics in Mathematics Education," Int. J. Sci. Math. Educ., vol. 18, no. 1, 2020. https://doi.org/10.1007/s10763018-09939-y

[9] E. Jurado, D. Fonseca, J. Coderch, and X. Canaleta, "Social steam learning at an early age with robotic platforms: A case study in four schools in Spain," Sensors, vol. 20, no. 13, 2020. https://doi.org/10.3390/s20133698

[10] H. Chen, H. W. Park, and C. Breazeal, "Teaching and learning with children: Impact of reciprocal peer learning with a social robot on children's learning and emotive engagement," Comput. Educ., vol. 150, 2020. https://doi.org/10.1016/j.compedu.2020.103836

[11] L. Belmonte, E. Segura, A. Fernández-Caballero, and R. Morales, “Towards industry 4.0: Using LEGO MINDSTORMS and ANDROID for the development of final degree projects in industrial engineering programs," in INTED2020 Proceedings, 2020, vol. 1. https://doi.org/10.21125/inted.2020.0879

[12] E. Tosello, N. Castaman, and E. Menegatti, "Using robotics to train students for Industry 4.0," in $I F A C$ PapersOnLine, 2019, vol. 52, no. 9. https://doi.org/10.1016/j.ifacol.2019.08.185

[13] A. T. Talib, M. A. Mohd, A. S. Baharuddin, M. N. Mokhtar, and M. Wakisaka, "Mechanical characterisation of lignocellulosic fibres using toy bricks tensile tester," J. Mech. Behav. Biomed. Mater., vol. 97, 2019. https://doi.org/10.1016/j.jmbbm.2019.05.010

[14] G. Lugaresi, N. Frigerio, and A. Matta, "A new learning factory experience exploiting LEGO for teaching manufacturing systems integration," in Procedia Manufacturing, 2020, vol. 45. https://doi.org/10.1016/j.promfg.2020.04.106

[15] J. Lindh and T. Holgersson, "Does lego training stimulate pupils' ability to solve logical problems?," Comput. Educ., vol. 49, no. 4, 2007. https://doi.org/10.1016/j.compedu.2005.12.008

[16] Y. B. Kafai, "Constructionist visions: Hard fun with serious games," Int. J. Child-Computer Interact., vol. 18, 2018. https://doi.org/10.1016/j.ijcci.2018.04.002

[17] J. S. Brown, P. Duguid, and A. Collins, "Situated Cognition the Culture of Learning," Educ. Res., vol. 18, no. 1, 2014. https://doi.org/10.3102/0013189X018001032 
[18] G. Fragkiadaki and K. Ravanis, "The unity between intellect, affect, and action in a child's learning and development in science," Learn. Cult. Soc. Interact., vol. 29, 2021. https://doi.org/10.1016/j.lcsi.2021.100495

[19] H. Chowdhury, F. Alam, and I. Mustary, "Development of an innovatiove technique for teaching and learning of laboratory experiments for engineering courses," in Energy Procedia, 2019, vol. 160. https://doi.org/10.1016/j.egypro.2019.02.154

[20] H. K. Kondaveeti, N. K. Kumaravelu, S. D. Vanambathina, S. E. Mathe, and S. Vappangi, "A systematic literature review on prototyping with Arduino: Applications, challenges, advantages, and limitations," Computer Science Review, vol. 40. 2021. https://doi.org/10.1016/j.cosrev.2021.100364

[21] C. W. Chang, J. H. Lee, C. Y. Wang, and G. D. Chen, "Improving the authentic learning experience by integrating robots into the mixed-reality environment," Comput. Educ., vol. 55, no. 4, 2010. https://doi.org/10.1016/j.compedu.2010.06.023

[22] M. Lei, I. M. Clemente, and Y. Hu, "Student in the shell: The robotic body and student engagement," Comput. Educ., vol. 130, 2019. https://doi.org/10.1016/j.compedu.2018.11.008

[23] M. Pienimäki, M. Kinnula, and N. Iivari, "Finding fun in non-formal technology education," Int. J. ChildComputer Interact., vol. 29, 2021. https://doi.org/10.1016/j.ijcci.2021.100283

[24] B. Y. Shih, T. H. Chen, S. M. Wang, and C. Y. Chen, "The exploration of applying lego nxt in the situated science and technology learning," J. Balt. Sci. Educ., vol. 12, no. 1, 2013. http://www.scientiasocialis.lt/jbse/?q=node/280

[25] M. Koivuniemi, H. Järvenoja, and S. Järvelä, "Teacher education students' strategic activities in challenging collaborative learning situations," Learn. Cult. Soc. Interact., vol. 19, 2018. https://doi.org/10.1016/j.lcsi.2018.05.002 